\title{
I 0 I 8 Safety of cardiovascular magnetic resonance performed immediately after primary percutaneous coronary intervention for ST-elevation myocardial infarction
}

\author{
Julie Cote, Josep Rodes, Bernard Brochu, Santiago Miro, Bernard Noel, \\ Gerald Barbeau, Robert Delarochelliere, Olivier Bertrand and Eric Larose*
}

Address: Quebec Heart Institute at Laval Hospital, Quebec, QC, Canada

* Corresponding author

from I th Annual SCMR Scientific Sessions

Los Angeles, CA, USA. I-3 February 2008

Published: 22 October 2008

Journal of Cardiovascular Magnetic Resonance 2008, I0(Suppl I):AI43 doi:I0.II86/I532-429X-I0-SI-AI43

This abstract is available from: http://jcmr-online.com/content/I0/SI/AI43

(c) 2008 Cote et al; licensee BioMed Central Ltd.

\section{Background}

After percutaneous coronary intervention (PCI) with stent implantation, cardiovascular magnetic resonance (CMR) is usually postponed in order to prevent theoretical stent heating or displacement. However, several studies have demonstrated CMR safety when performed 3 days after the PCI procedure. In order to better evaluate myocardial perfusion, necrosis and viability in the hyperacute phase of ST elevation myocardial infarction (STEMI), it would be useful to perform CMR more rapidly following coronary stenting. We investigated the early and long term safety of CMR when performed immediately after primary PCI with stenting for STEMI.

\section{Methods}

We prospectively studied 128 patients undergoing primary PCI with stent implantation for STEMI. The study group was composed of 64 patients who underwent CMR (1.5 Tesla) within 12 hours after primary PCI including 105 stents. The control group, also composed of 64 patients, underwent primary PCI without CMR. Adverse events were reported during the early in-hospital period as well as during 6-month follow-up.

\section{Results}

Patient populations were comparable in both groups. Total ischemic times were similar (CMR+ $4.0 \mathrm{~h}$, CMR- 5.5 $\mathrm{h}, \mathrm{p}=\mathrm{ns})$, as were peak troponin rise $(\mathrm{CMR}+3.2 \mu \mathrm{g} / \mathrm{L}$, CMR- $2.3 \mu \mathrm{g} / \mathrm{L}, \mathrm{p}=\mathrm{ns}$ ). The median delay between PCI and CMR was 4.8 (interquartile range 4.1) hours. Duration of the CMR study was 42 (11) minutes and no adverse events occurred during the imaging session. Immediate CMR was not associated with any in-hospital increase in death, myocardial infarction, urgent revascularization, or bleeding ( $\mathrm{p}=\mathrm{ns}$ for each). During 6-month follow-up, CMR performed immediately after primary PCI was not associated with a higher rate adverse events compared to primary PCI without CMR (respectively MACE 5 vs. $8 \%, \mathrm{p}=0.16$; repeat angina 6 vs. $8 \%, \mathrm{p}=0.73$; rehospitalization for cardiac cause 3 vs. $13 \%, \mathrm{p}=0.05$ ). On Kaplan-Meier estimates, event-free survival at 6 months was not decreased by performing CMR immediately after primary PCI with stenting.

\section{Conclusion}

Cardiovascular magnetic resonance at $1.5 \mathrm{~T}$ performed immediately after primary PCI with coronary stent implantation has proven early and long-term safety, opening the door for improved risk stratification in the hyperacute phase of STEMI. 